\title{
INCIDENCE OF SEXUALLY TRANSMITTED DISEASES AMONGST POTENTIAL SEMEN DONORS IN UNIVERSITY OF BENIN TEACHING HOSPITAL, BENIN CITY, NIGERIA
}

*O.K Ibadin (M.Sc), ** I.O Enabulele (Ph.D)

*Human Reproduction Research Programme/Invitro Fertilization Unit, University of Benin Teaching Hospital, Benin City, Nigeria.

${ }^{* *}$ Department Of Microbiology, University of Benin, Nigeria.

\section{Correspondence:}

Ibadin O.K.

Human Reproduction Research Programme/IVF Unit

Dept. of Obstetric \& Gynaecology

University of Benin Teaching Hospital,

Benin City, Nigeria.

E-mail: kenbadin2@yahoo.com

\section{ABSTRACT}

The incidence of Sexually Transmitted Diseases in Prospective Semen Donors where investigated using Standard Laboratory Procedures. 30 Prospective Semen Donors were screened for common STDs/STI at the Human Reproductive Research Programme IInvitro Fertilization Centre of the University of Benin Teaching Hospital. The incidence rates are Staphylococcus aureus (20\%), followed by Chlamydia trachomatis (6.7\%) while Klebsiellia spp, Treponema pallidum, Human Immunodeficiency Virus (HIV), Escherichia coli and Hepatitis B Virus were detected with incidence rate of $3.3 \%$ each respectively. Ten percent $(10 \%)$ of the prospective semen donors had evidence of polymicrobial infection excluding HIV. The risk of sexually transmitted diseases or infection should be of great concern to couples undergoing therapeutic artificial donor insemination.

Keywords: STDs/STI, Artificial Insemination, Semen Donors)

\section{INTRODUCTION}

Therapeutic donor insemination has become well-established option in the treatment of un-correctable malefactor infertility. The use of donor semen has increased dramatically in recent years and thousands of infants are conceived worldwide by artificial insemination with the use of donor semen. Despite its wide acceptance among physicians and infertile couples, recent reports of contaminated semen continue to cause considerable concern ${ }^{2,3}$. Many individuals presenting as potential semen donors, who are infected with several pathogens may lack symptoms and signs of infection, or may not have clinically detectable evidence of infection, thereby placing the recipient at significant risk. Efforts to reduce the risk of transmitting infection during artificial insemination with donor semen include adoption of the guidelines recommended by the American Fertility Society. These guidelines recommend rigorous

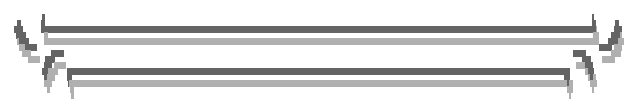


screening of Potential semen donors for sexually transmitted disease (STDs) and that the sperm be frozen and quarantined for a period of six to twelve months while the donor undergoes repeated testing for development of antibodies to the human immunodeficiency virus (HIV) ${ }^{4}$.

Despite the comprehensive guidelines of several professional and governmental agencies screening therapeutic insemination donors for sexually transmitted disease, available data suggest that the standard of practice is highly variable ${ }^{7}$. Several programmes appear to take inadequate measures to prevent STD transmission by limiting screening to entry only without frequent retesting, while some continue to use fresh sperm and content that the recommended screening procedures are cumbersome and expensive. The long-term sequela of infecting a healthy semen recipient with STDs clearly justifies rigorous screening, although this practice may reduce the pool of suitable donors. These guidelines are not being universally applied. Not only do some donor insemination programmes especially in developing countries, continue to use fresh semen ${ }^{5,6}$. Others use semen cultures as an alternative to urethral cultures inspite of the paucity of data on the reliability of semen cultures as a screening too ${ }^{7}$.

Previous studies have reported the Incidence of Sexually Transmitted Diseases among Potential Semen Donors. From June 1986 through August 1987 in Houston Texas, for 48 healthy male volunteers presented as potential semen donors. $10 \%$ of the donor had evidence of sexually transmitted disease $e^{1,3,9}$.
The main focus of this study, and focus is to ascertain the incidence of Common Sexually Transmitted Pathogens in male subjects Presenting to our Clinic as Prospective Semen Donors using current screening guidelines.

\section{MATERIALS AND METHODS}

32 prospective semen donors, ranging in age from 30 to 40years were recruited of the Human Reproduction Research Programme/Invitro Fertilization Centre of the Hospital from January 2007 to August 2008. Semen, urine, Urethral discharge and blood were collected from each of the donor.

All of the samples were rapidly transferred to Microbiology Lab of the Hospital and Standard Microbiology Techniques was performed to detect the microbial agents (on Blood agar, MacConkey and Chocolate agar for Bacteriogical culture incubated at $37^{\circ}$ Celcius for 24-48hours. After Incubation Period, Specific diagnostic tests according to microbiology references were performed to reorganize the known colonies $^{8,10}$. In addition, Standard Serological Methods were applied for the detection of Treponema palladum, Chlamydia trachomatis and Human Immunodeficiency Virus in blood samples. Semen parameter was performed according to World Health Organization Guidelines ${ }^{14}$.

\section{RESULTS}

Demographic characteristic of the Prospective Semen Donors, showed a predominantly single male in heterosexual relationship and $30 \%$ gave a history of at least one previous episode of Sexually Transmitted Diseases (STDs). A total of $15(50 \%)$ 
microbial agents were isolated from the 30 Prospective Donors screened within the period under study. Staphylococcus aureus had $6(20 \%)$ followed by Chlamydia trachomatis 2(6.\%), while Klebsielia spp, Treponema pallidum Human Immunodeficiency Virus,
Esacherichia coli and Hepalitis B Virus had $3.3 \%$ incidence rate. $3(10 \%)$ had evidence of Polymicrobial Infection excluding Human Immunodeficiency Virus. Positive findings in this study were predicted by history of more than one partner.

TABLE I: AGE CLASSIFICATION OF SEMEN DONORS WITH SEXUALLY TRANSMITTED DISEASES

\begin{tabular}{llll}
\hline Age (Yrs) & Numb. Exam. & Numb. Positive & \% Positive \\
\hline $20-24$ & 10 & 4 & 40 \\
$25-29$ & 14 & 10 & 71 \\
$30-34$ & 3 & 1 & 33 \\
$35-39$ & 2 & 0 & 0 \\
$>40$ & 1 & 0 & 0 \\
\hline Total & 30 & 15 & 50 \\
\hline
\end{tabular}

\section{TABLE II: NUMBER OF MICROBIAL PATHOGEN PER SPECIMEN FROM PROSPECTIVE SEMEN DONORS IN UBTH}

Microbial pathogen

\begin{tabular}{|c|c|c|c|c|c|}
\hline & Urethral discharge & Urine & Semen & Blood & Total \\
\hline Staphylococcus aureus & $5(16 \%)$ & $(0 \%)$ & $3(10 \%)$ & - & $6(20 \%)$ \\
\hline Klebsiellia Spp. & $0(0 \%)$ & $(0 \%))$ & $1(3.3 \%$ & - & $1(3.3 \%)$ \\
\hline Escherichia coli & $0(0 \%)$ & $1(3.3 \%)$ & $0(0 \%)$ & & $1(3.3 \%)$ \\
\hline Chlamydia trachomatis & - & - & - & $2(6.7 \%)$ & $2(6.7 \%)$ \\
\hline Treponema pallidum & - & - & - & $1(3.3 \%)$ & $1(3.3 \%)$ \\
\hline Human Immunodeficiency Virus & - & - & - & $1(3.3 \%)$ & $1(3.3 \%)$ \\
\hline Hepatitis B Virus & - & - & - & $1(3.3 \%)$ & $1(3.3 \%)$ \\
\hline Total & $5(16.7 \%)$ & $1(3.3 \%)$ & $4(13.3 \%)$ & $5(16.7 \%)$ & $5(50 \%)$ \\
\hline
\end{tabular}




\section{DISCUSSION}

Artificial insemination with donor semen has become a well established alternative for couples with untreatable male factor infertility. Because of the widespread use of donor insemination, and the increasing awareness and prevalence of sexually transmitted diseases, It has become imperative to subject prospective semen donors for sexually transmitted screening.

The incidence rate of sexually transmitted disease from this study was $50 \%$ which underscore the concern often expressed by women undergoing artificial inseminations with donor sperm regarding the risk of being infected with sexually transmitted pathogen.

Chlamydia trachomatis ranked second in the incidence of STDs in this study. Its manifestations are well acknowledged in women whom it is responsible for majority of cases of salpingitis ${ }^{7}$. Prospective semen donors with seroevidence of HIV were rejected. In one of the study carried out by Mark et $a l^{12}$, the infection rate in 44 enlisted semen donors in some fertility centres in Canada is $13.6 \%$ as against $50 \%$ from the 30 Semen Donors enlisted in this study. It should be noted that $3(10 \%)$ out of the total number enlisted in this study had positive evidence of Polymicrobial infections particularly from Urethral and Semen Samples from this individuals. It was also observed that prospective donors in the age group of 25-29 had the highest incidence of STD of $10(71 \%)$, which also underscore the need to educate and enlighten our youths on the danger of acquiring these pathogen.

Consistent with previous studies this finding strengthens the fact that Prospective Semen Donors, most of whom are young, single, and are not always in monogamous relationships, represent a high-risk population for STD transmission. This predominantlystudent population requires rigorous screening and frequent retesting for the acquisition of new pathogens. Establishing a rapport and good communication with this group of highly fertile donors, with emphasis on the importance of responsible, safe sexually behaviours is suggested. The incidence of Sexually Transmissible Infections in Prospective Semen Donors has been reported in some centres controversy remains concerning the extent of screening that is appropriate for semen donors. The major question is whether or not the benefit of reducing the risk of transmitting STDs compensates for the cost of vigorous screening. As screening methods continue to improve, and more data accumulate on the outcome of frequent testing, it appears that such a meticulous approach to screening is appropriate. With such close surveillance and management, the transmission of pathogens to semen recipients may hopefully be reduced to the minimum.

\section{REFERENCES}

1. Stewart GJ, Tyler JPP, Cunningham AL et al. Transmission of human T-Cell Lymphotropic virus. Type III (HTL VIII) by artificial insemination by donor. Lancet 1981; 2:581-584.

2. Monteiro EF, Spencer RC, Kinghorn GR et al, Sexually transmitted disease in potential semen donors. Br. Med J. 1987; 295:418. 
3. Anderson DJ. Wolff $\mathrm{H}$, Pudorey et al. Presence of HIV in semen in: Alexander, NJ, Gablenick HL, Spieler, JM. (eds). 1990.

4. Heterosexual transmission of AIDS. New York, Wiley L\&; 167.

5. American Fertility Society: New guidelines for the use of semen donor insemination: Fertile Sterile 1990: 53 (Supply 1): 15.

6. Barratt, CLR, Monteiro EF, Chauhan M, Cooke S, Cooke ID. Screening for sexually transmitted disease in door insemination clinics in the UK. A survey. Br. J. Obste Gynecol. 1989; 96: 461-466.

7. Barratt, CLR, Li TC, Monteiro EF. Diagnosis and detection of male accessory gland infection. In: Barrett CLR. 1988.

8. CheesbroughM. Medical Laboratory Manual for Tropical Countries. Vol. II. Microbiology. $2^{\text {nd }}$ ed. University Press. Cambridge. 1984: 100-196.

9. Cooke, I.D. (eds). Advances in clinical andrology. MTP press, Lancaster, 91-98.
10. Cowan ST, Steel KJ. Manual for the identification of Medical Bacteria, $4^{\text {th }}$ ed. Cambridge University Press. London1985 pp. 217

11. Tjiam KH, Van Heijst, BYM, Polak-Vogelvang AA et al. Sexually communicable microorganisms in human semen samples to be used for artificial inseminating by donor. Genitourin Med. 1987; 63; 116-118.

12. Marks JL, Marks D, Lipshultz LI. Artificial insemination with donor semen: the necessity of frequent donor screening. J. Urol. 1990; 143: 308-310.

13. Leiva JJ. Peterson EM, Wetkowski E et al. Microorganism in semen used for artificial insemination. Obstet Gynaecol. 1985; 65:669.

14. World Health Organization Laboratory manual for the examination of human semen and sperm-cervical mucus interaction $4^{\text {th }}$ ed. Cambridge University Inc. Cambridge, UK, pp: 1-138.

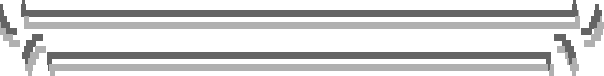

